\title{
Endovascular Repair of Abdominal Aortic Aneurysm May Not Provide Long-Term Survival Benefit
}

\author{
R. Englund, N. Katib \\ Department of Vascular Surgery, St George Private Hospital, Kogarah, Australia \\ Email: renglund@ihug.com.au
}

Received 11 June 2016; accepted 8 July 2016; published 11 July 2016

Copyright (C) 2016 by authors and Scientific Research Publishing Inc.

This work is licensed under the Creative Commons Attribution International License (CC BY).

http://creativecommons.org/licenses/by/4.0/

(c) (7) Open Access

\begin{abstract}
Purpose: To investigate the long term survival benefit for the treatment of abdominal aortic aneurysmal (AAA) disease with Endovascular Aneurysm Repair (EVAR). Our hypothesis is that patients undergoing EVAR have an equivalent survival to an age matched population. Methods: Between 1997 and 2014 all patients treated for an AAA with EVAR by a single surgeon were prospectively followed and at 12 monthly intervals ultrasonography was utilised to assess the size of the aorta after treatment. Data from the Births, Deaths and Marriages was also collected regarding the survival of these patients. As of 2003 all patients with AAA were treated electively with EVAR. Results: There were a total of 145 patients treated with EVAR for AAA during the study period, 143 who survived the 30-day post-operative period. The long-term survival following EVAR at one year was $95 \%$ (95\% C.I.: 88\% to 97\%), at 5 years 56\% (95\% C.I.: $42 \%$ to 64\%), and at 10 years $28 \%$ (95\% C.I.: $17 \%$ to $42 \%$ ). Compared to an age-matched population the EVAR group had a lower than expected long term survival $(P<\mathbf{0 . 0 0 0 1})$. Discussion: EVAR for the treatment of abdominal aortic aneurysms can be achieved with acceptable 30 day survival and freedom from aneurysm related death. However selection of patients for EVAR may significantly effect long-term survival if patients are fit for EVAR but not open operation. The question arises as to whether EVAR should be performed in patients with questionable long-term survival, even if they are fit for this procedure.
\end{abstract}

\section{Keywords}

Endovascular, Abdominal Aortic Aneurysm, Survival

\section{Introduction}

Abdominal Aortic Aneurysm (AAA) disease (defined as an outer abdominal aortic wall diameter $\geq 3 \mathrm{~cm}$ ) in a 
screening study was found to have a higher prevalence in men (up to 7.6\%) than women (1.3\%) [1]. Endovascular repair of abdominal aortic aneurysms has been demonstrated in clinical trials [2] [3] to result in a lower 30-day mortality rate when compared to open surgical repair. However the EVAR 2 Trial [4] demonstrated that in patients not fit for open repair, the performance of EVAR provided no survival benefit. Furthermore the Dream trial bracket [5] participants reported a 5-year survival follow-up concluding no benefit for EVAR compared to open repair. With the exception of the EVAR 2 Trial all patients entering these trials above were selected because they were fit to undergo either EVAR or open repair. A report from the EUROSTAR Registry [6], found, "the mid-term outcome of large aneurysms after EVAR was associated with an increased rate of aneurysm related death, unrelated death and rupture”. Brewster et al. [7] in a similar registry report, in which $20 \%$ of the patient's were unfit for open repair, concluded "EVAR using contemporary devices is a safe, effective and durable method to prevent aortic aneurysm rupture and aneurysm related death.”

In the light of this information this report examines the long-term outcome of abdominal aortic aneurysm patients undergoing EVAR performed by the author. The primary end point of this study was survival benefit for the treatment of abdominal aortic aneurysms by EVAR. The hypothesis to be tested was that patients undergoing EVAR had an equivalent survival compared to an age-matched population.

\section{Methods}

Patients who were the subject of this study are all patients who had an EVAR for the treatment of an abdominal aortic aneurysm by the author between 1997 and 2014. A prospectively collected database was created from the medical records of these patients. Following EVAR all patients were followed at 12 monthly intervals. When an endo-leak or increasing size of aneurysm was detected a CT angiography study was performed. Some of these patients subsequently underwent catheter aortography to identify the nature of the endoleak.

Where follow-up data was not available, this data was obtained via the Centre for health record linkage (CheRel) and from the Registry of Births, Deaths and Marriages New South Wales Government.

Ethics approval for this study was provided by the Centre for Population Health and Research, Department of Health New South Wales. All data was analysed statistically by Power Stats TM. Statistical analysis was by stratification into treatment groups, construction of Kaplan Meier survival curves and comparison by ManWhitney statistical testing and statistical significance was taken as a p value less than or equal to 0.05 .

The decision to offer EVAR to all patients from 2003 in preference to open repair was made due to the possibility of avoidance of clamp/declamping stress, percutaneous approach and the potential reduced hospital stay. All patients undergoing EVAR underwent CT angiography as a first step in selection and planning of the procedure. Treatment was indicated if the aortic diameter was greater than $5-5.5 \mathrm{~cm}$. Aortic aneurysms with an unfavourable neck diameter and length were considered for fenestrated grafting and when applicable this was undertaken. Similarly where iliac artery anatomy was unfavourable an iliac bifurcation device (Iliac Bracnched Device by Cook Medical) was considered. No patient underwent an elective open repair of an aortic aneurysm after 2003.

\section{Results}

EVAR was performed for the treatment of abdominal aortic aneurysms in 145 patients between 1997 and 2014. The use of fenestrated grafts (Cook medical TM), with or without IBD, or IBD alone, was performed in 11 patients. Three patients died in the 30 day post-operative period. One patient died from aspiration pneumonia post-operatively in the high dependency unit. Another patient died as a result of leaking colonic anastomosis, which had been performed by anterior colonic resection for carcinoma of the colon one week following EVAR. The third patient died from acute myocardial infarction. The 30 day mortality rate was $2 \%$. This left 142 patients suitable for assessment with respect to long-term survival following EVAR.

Males accounted for $85 \%$ of the patient's. Patient's over 80 years of age accounted for $35 \%$ of the patient population (Table 1).

Endo-leaks were detected in 9 patients at follow-up. Type 1 Endo-leak was detected in two patients at 9 and 10 years post-operative. Type II endo-leaks were detected in 6 patients. One patient had a combined type II and type III endo-leak. The inferior mesenteric artery appeared to be the source of the endo-leak in 4 of the type II endo-leaks. The remaining Type II endo-leaks appeared to arise from the lumbar arteries at the lower end of the aorta. 
Table 1. Age distribution of patients undergoing EVAR.

\begin{tabular}{cccc}
\hline & $->$ Procedure Type $=$ Elective Abdominal Evar & \\
\hline Age group 1 & Freq. & Percent & Cum. \\
\hline under 70 & 34 & 23.45 & 23.45 \\
$70-75$ & 29 & 20.00 & 43.45 \\
$76-80$ & 32 & 22.07 & 65.52 \\
Over 80 & 50 & 34.48 & 100.00 \\
Total & 145 & 100.00 & \\
\hline
\end{tabular}

One 90-year-old male with a type II endo-leak from the inferior mesenteric artery was treated initially with embolisation of the inferior mesenteric artery via direct sac puncture. He represented within 3 months with an infected aneurysm sac and graft. He died following graft removal and extra anatomical bypass graft.

The endo-leak rate was $6.3 \%$ for 142 surviving EVAR patients.

The long-term survival following EVAR at one year was 95\% (95\% C.I.: 88\% to 97\%), at 5 years 56\% (95\% C.I.: $42 \%$ to $64 \%$ ), and at 10 years $28 \%$ (95\% C.I.: $17 \%$ to $42 \%)$. There was a significant difference in longterm survival following EVAR and a correspondingly age-matched population (Figure 1, P < 0.0001)

\section{Discussion}

The use of EVAR was initially developed technically in the last decade of the $20^{\text {th }}$ century [8] [9]. Subsequently the development of registries [10] [11] established the parameters around which clinician's could expect EVAR to be applicable in clinical situations. The first decade of the $21^{\text {st }}$ century established that in patients who were fit for an open repair of AAA, the performance of EVAR resulted in a lower 30 day mortality rate, a lower surgical complication rate and a shorter hospital stay [2] [3]. In 2010 the DREAM trial participant's found that 6 years after randomisation, survival rates for EVAR and open repair were equivalent but secondary interventions were significantly higher for the endovascular repair group [5].

With respect to all these reports, the caveat on treatment by EVAR was predicated on appropriate aneurysm anatomy. Whereas the EVAR 1 trial consisted of aorto-uni-iliac usage in $10 \%$ of patients, this would be less applicable currently. During the second decade of the $21^{\text {st }}$ century medical device development has been focused on stent grafts with a lower delivery device profile, full support by stents throughout the device, suprarenal fixation of stent grafts and extension of anatomical limitations by the usage of fenestrated and branch devices to deal with proximal anatomical issues and iliac bifurcations devices to deal with distal anatomical issues. Additionally modular device construction has significantly improved accessibility and reduced costs for the performance of EVAR. Furthermore, patients with a contrast allergy or renal impairment can often be managed with a combination of carbon dioxide and/or gadolinium based imaging. It is not unimaginable that ultimately EVAR could be performed entirely by ultrasound-guided imaging. In our opinion there is currently practically no contraindication to the performance of EVAR with one exception. This exception was demonstrated by the EVAR 2 trial [4]. This trial compared the management of aortic aneurysm by either EVAR or with conservative treatment for those patients unfit for open surgery. The trial demonstrated no benefit for EVAR over conservative treatment. As an alternative registries [7] [12] of EVAR for aortic aneurysms have chosen to use freedom from aneurysm related death as an alternative end point to long-term survival. Age at time of operation is one of the strongest predictors of long-term survival [13] [14]. Mortality rates also have been demonstrated to be significantly higher in patients over 80 years of age. Similarly not all patients with aortic aneurysms died as a result of aneurysm related events. For patients treated non-surgically for aortic aneurysm the author [15] found that 5 year survival for patients with aortic aneurysms greater than $5 \mathrm{~cm}$ in diameter was $25 \%, 40 \%$ of these were due to cardiopulmonary events while only $30 \%$ were due to aneurysm rupture. Similar findings to this had been reported previous to this study [16].

Given this background it seems highly improbable that an informed patient would accept open repair of abdominal aortic aneurysm over EVAR. The question addressed by the current study is whether, given the current status of technology for EVAR, repair of aortic aneurysms by current EVAR methods provides long-term survival benefit. Patients in this study were selected for EVAR because they were fit for this operation. No open 


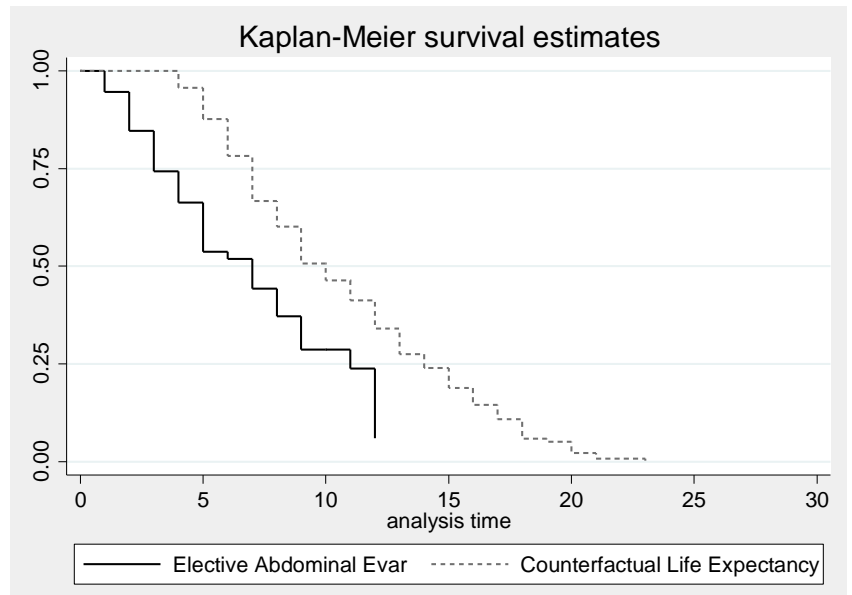

Figure 1. Long-term survival of EVAR patients versus an aged matched population.

repairs were offered after 2003. The anatomical constraints posed by the EVAR 1 trial were not applicable to this group. During the period from 1987 to 2003 when the author performed aneurysm repair predominantly by open techniques the survival rates at 1, 5 and 10 years was 93\% (95\% C.I. 89\% - 96\%), 72\% (95\% C.I. 65\% 78\%) and 40\% (95\% C.I. 33\% - 47\%) respectively [17]. Between 1997 and 2003 there was a change over period during which the performance of EVAR was developed at the institution where the author worked. Following this learning curve for EVAR, this operation was performed exclusively and the survival rates at 1,5 and 10 years were $95 \%$ (95\% C.I. $88 \%$ - 97\%), 53\% (95\% C.I. $42 \%$ - 64\%) and 28\% (95\% C.I. $17 \%$ - 42\%) respectively. Although the 30-day mortality rates were similar over the two periods, there appears to be a long-term difference in survival. We have tried to avoid making comparisons between open aortic aneurysm repair and EVAR because of the different time periods over which these two techniques were performed. This difference may be due to the different selection criteria used for EVAR patients.

Other authors [18] have not considered this time discrepancy to be significant. In our study $35 \%$ of the patient's were over 80 years of age and 15\% of the patient's were female. In the EVAR 1 trial the mean age of patients was 74 years and only $9 \%$ were female. This low rate of selection of female patients may have been based on the anatomical factor that prior to 2004 lower profile delivery devices were not available. The poor outcome for females with aneurysmal disease is well recognised [19].

The paradox for either may well be that as technological developments in stent graft design progress, its applicability may become so universal that while avoidance of aneurysm related death may be achieved, long-term survival may not be improved particularly in ageing populations.

\section{Conclusion}

This study has demonstrated that the performance of EVAR can be achieved with acceptable 30-day mortality rates and satisfactory endo-leak incidence and the avoidance of aneurysm related death without achieving comparable long-term survival benefit compared to a theoretically age-matched population. The question arising from the study is when and can EVAR be withheld for the treatment of aortic aneurysm disease.

\section{References}

[1] Norman, P.E. and Powell, J.T. (2007) Contemporary Reviews in Cardiovascular Medicine, Abdominal Aortic Aneurysm, The Prognosis in Women Is Worse Than In Men. Circulation, 115, 2865-2869. http://dx.doi.org/10.1161/CIRCULATIONAHA.106.671859

[2] Greenhalgh, R.M. (2004) Comparison of Endovascular Aneurysm Repair with Open Repair in Patients with Abdominal Aortic Aneurysm (EVAR Trial 1), 30-Day Operative Mortality Results: Randomised Controlled Trial. The Lancet, 364, 843-848. http://dx.doi.org/10.1016/S0140-6736(04)16979-1

[3] Prinssen, M., et al. (2004) A Randomized Trial Comparing Conventional and Endovascular Repair of Abdominal Aortic Aneurysms. New England Journal of Medicine, 351, 1607-1618. http://dx.doi.org/10.1056/NEJMoa042002 
[4] De Bruin, J.L., Baas, A.F. and Buth, J. (2010) Long-Term Outcome of Open or Endovascular Repair of Abdominal Aortic Aneurysm. Journal of Vascular Surgery, 52, 518.

[5] EVAR Trial Participants (2005) Endovascular Aneurysm Repair and Outcome in Patients Unfit for Open Repair of Abdominal Aortic Aneurysm (EVAR Trial 2): Randomized Controlled Trial. The Lancet, 365, 2187-2192. http://dx.doi.org/10.1016/S0140-6736(05)66628-7

[6] Peppelenbosch, N., et al. (2004) Diameter of Abdominal Aortic Aneurysm and Outcome of Endovascular Aneurysm Repair: Does Size Matter? A Report from EUROSTAR. Journal of Vascular Surgery, 39, 288-297. http://dx.doi.org/10.1016/j.jvs.2003.09.047

[7] Brewster, D.C., et al. (2006) Long-Term Outcomes after Endovascular Abdominal Aortic Aneurysm Repair. The First Decade. Annals of Surgery, 244, 426-438.

[8] Volodos, N.L., Shekham, V.E., Karpovich, I.P., et al. (1986) A Self-Fixing Synthetic Blood Vessel Endoprosthesis. VestnKhirImGrek, 137, 123-125.

[9] Parodi, J.C., Palmaz, J.C. and Barone, H.D. (1991) Transfemoral Intraluminal Graft Implantation for Abdominal Aortic Aneurysms. Annals of Vascular Surgery, 5, 491-499. http://dx.doi.org/10.1007/BF02015271

[10] Thomas, S.M, Gaines, P.A. and Beard, J.D. (2001) Short-Term (30-Day) Outcome of Endovascular Treatment of Abdominal Aortic Aneurysm: Results from the Prospective Registry of Endovascular Treatment of Abdominal Aortic Aneurysms (RETA). European Journal of Vascular and Endovascular Surgery, 21, 57-64. http://dx.doi.org/10.1053/ejvs.2000.1268

[11] Harris, P.L., et al. (1997) The Need for Clinical Trials of Endovascular Abdominal Aortic Aneurysm Stent-Graft Repair: The EUROSTAR Project. Journal of Endovascular Therapy, 4, 72-77.

[12] (2005) Lifeline Registry of Endovascular Aneurysm Repair: Long-Term Primary Outcome Measures. Journal of Vascular Surgery, 42, 1-10. http://dx.doi.org/10.1016/j.jvs.2005.05.012

[13] Treiman, R.L., et al. (1982) Aneurysmectomy in the Octogenarian. The American Journal of Surgery, 144, $194-197$. http://dx.doi.org/10.1016/0002-9610(82)90506-2

[14] Robinson, D., Englund, R. and Hanel, K.C. (1997) Treatment of Abdominal Aortic Aneurysm Disease in the 9th and 10th Decades of Life. Australian and New Zealand Journal of Surgery, 67, 640-642. http://dx.doi.org/10.1111/j.1445-2197.1997.tb04615.x

[15] Englund, R., Perera, D. and Hanel, K.C. (1997) Outcome for Patients with Abdominal Aortic Aneurysms That Are Treated Non-Surgically. Australian and New Zealand Journal of Surgery, 67, 260-263. http://dx.doi.org/10.1111/j.1445-2197.1997.tb01959.x

[16] Søreide, O., et al. (1982) Time and Cause of Death for 301 Patients Operated on for Abdominal Aortic Aneurysms. Age and Ageing, 11, 256-260. http://dx.doi.org/10.1093/ageing/11.4.256

[17] Katib, N. and Englund, R. (2016) Long Term Survival Following Open Repair of Ruptured Abdominal Aortic Aneurysm. Awaiting Publication. (In Press)

[18] Khashram, M., et al. (2015) Long-Term Outcomes And Factors Influencing Late Survival Following Elective Abdominal Aortic Aneurysm Repair: A 24-Year Experience. Vascular, 24, 115-125. http://dx.doi.org/10.1177/1708538115586682

[19] Norman, P. (2001) Long-Term Relative Survival Following Surgery For Abdominal Aortic Aneurysm: A Review. Cardiovascular Surgery, 9, 219-224. http://dx.doi.org/10.1016/S0967-2109(00)00126-5 


\section{Submit or recommend next manuscript to SCIRP and we will provide best service for you:}

Accepting pre-submission inquiries through Email, Facebook, Linkedin, Twitter, etc A wide selection of journals (inclusive of 9 subjects, more than 200 journals)

Providing a 24-hour high-quality service

User-friendly online submission system

Fair and swift peer-review system

Efficient typesetting and proofreading procedure

Display of the result of downloads and visits, as well as the number of cited articles

Maximum dissemination of your research work

Submit your manuscript at: http://papersubmission.scirp.org/ 